\title{
Therapy of chronic hepatitis $C$ in people who inject drugs: focus on adherence
}

\author{
Sona Frankova ${ }^{1^{*}}$ (D) Z Zuzana Jandova ${ }^{2,6}$, Gabriela Jinochova ${ }^{2,3}$, Miluse Kreidlova ${ }^{4}$, Dusan Merta ${ }^{5}$ and Jan Sperl ${ }^{1,6}$
}

\begin{abstract}
Background: Intravenous drug use (IVDU) represents the major factor of HCV transmission, but the treatment uptake among people who inject drugs (PWID) remains low owing to a false presumption of low efficacy. The aim of our study was to assess treatment efficacy in PWID and factors determining adherence to therapy.

Methods: A total of 278 consecutive patients starting DAA (direct-acting antivirals) therapy were included, divided into two groups: individuals with a history of IVDU, PWID group $(N=101)$ and the control group $(N=177)$ without a history of IVDU.

Results: Sustained virological response 12 weeks after the end of therapy (SVR12) was achieved by 99/101 (98\%) and 172/177 (98\%) patients in the PWID and control group, respectively; in PWID group, two patients were lost to follow-up, and in the control group, four patients relapsed and one was lost to follow-up. PWID patients postponed appointments significantly more often, 29 (28.7\%) in PWID versus 7 (4\%) in the control group, $p=0.001$. Thirteen of 101 (12.9\%) and six of 177 (3.4\%) patients in the PWID and in the control group, respectively, missed at least one visit $(p<0.01)$. However, postponing visits led to a lack of medication in only one PWID. In the PWID group, older age $(p<0.05$; OR 1.07, 95\% Cl 1.00-1.20) and stable housing ( $p<0.01$; OR 9.70, 95\% Cl 2.10-56.20) were factors positively contributing to adherence. Contrarily, a stable job was a factor negatively influencing adherence $(p<0.05 ;$ OR 0.24 , $95 \% \mathrm{Cl} 0.06-0.81)$. In the control group, none of the analyzed social and demographic factors had an impact on adherence to therapy.
\end{abstract}

Conclusions: In PWID, treatment efficacy was excellent and was comparable with SVR of the control group. Stable housing and older age contributed to a better adherence to therapy.

Keywords: Adherence, Czech Republic, Drug user, Hepatitis C, PWID, Treatment

\section{Introduction}

Hepatitis $\mathrm{C}$ virus infection (HCV) is a significant source of preventable morbidity and mortality among persons who inject drugs (PWID) [1, 2]. In Western countries, as well as in the Czech Republic, intravenous drug use

\footnotetext{
*Correspondence: sona.frankova@ikem.cz

${ }^{1}$ Department of Hepatogastroenterology, Institute for Clinical

and Experimental Medicine, Videnska 1958/9, 14021 Prague, Czech Republic

Full list of author information is available at the end of the article
}

(IVDU) represents the major factor of $\mathrm{HCV}$ transmission, responsible for $50-80 \%$ of newly diagnosed cases [3, 4].

The prevalence of HCV infection in the population of PWID is high in comparison with general population and increases with the amount of time of ongoing IVDU [5, 6]. The Czech Republic is a country with low HCV prevalence (estimated prevalence in 2017: 0.5\%); however, the rate of anti-HCV-positive PWID is high: $67.5 \%[4,7,8]$. This group represents the most important epidemiologic risk of transmission of the virus in the population [1]. Furthermore, treatment of HCV infection not only leads to cure of $\mathrm{HCV}$-positive individuals, which prevents original author(s) and the source, provide a link to the Creative Commons licence, and indicate if changes were made. The images or other third party material in this article are included in the article's Creative Commons licence, unless indicated otherwise in a credit line to the material. If material is not included in the article's Creative Commons licence and your intended use is not permitted by statutory regulation or exceeds the permitted use, you will need to obtain permission directly from the copyright holder. To view a copy of this licence, visit http://creativecommons.org/licenses/by/4.0/. The Creative Commons Public Domain Dedication waiver (http://creativeco mmons.org/publicdomain/zero/1.0/) applies to the data made available in this article, unless otherwise stated in a credit line to the data. 
further progression of liver disease, but also represents a critical approach in prevention of onward transmission of the infection [2].

Available epidemiological data show that the numbers of treated individuals among PWID remain low. In the interferon era, only $1-2 \%$ of infected PWID were treated and they were excluded from nearly all early clinical trials of HCV treatment $[9,10]$. At the present time, $8 \%$ are treated in Australia and $7-16 \%$ in Canada and the USA [11-13].

Many barriers to HCV care in PWID have been identified; the major obstacle is a lack of treatment facilities suitable and adapted for PWID population [14]. When referred to secondary or tertiary centers, PWID often miss their appointments and they can suffer from stigmatization and face treatment refusal. The refusal or deferral of treatment is based on the false presumption of low treatment efficacy, bad adherence to therapy and a high risk of reinfection. However, several studies supporting evidence of high efficacy in PWID population have recently been published with sustained virological response (SVR, i.e., cure of the infection, defined as negative HCV RNA 12 or 24 weeks after treatment completion) rates exceeding $90 \%$ in patients with ongoing IVDU or on opioid substitution therapy [15-17].

In the Czech Republic, PWID are also perceived as a difficult-to-treat population and treatment of $\mathrm{HCV}$ in this group is deferred in many HCV-dedicated treatment centers. The aim of our study was to assess HCV treatment efficacy in PWID in comparison with individuals without a history of addiction with a special focus on factors influencing adherence to therapy.

\section{Methods}

All consecutive patients who initiated anti-HCV therapy at the outpatient department of Hepatogastroenterology Department at Institute for Clinical and Experimental Medicine, Prague, Czech Republic, between January 1, 2017, and August 6, 2018, were enrolled in order to evaluate SVR 12 and 24 weeks after the end of therapy. The cohort of patients was divided into two groups:

PWID group (PWID, $N=101)$ : patients with a history of intravenous drug use. Duration of abstinence from drug use did not influence treatment initiation: former, recent and ongoing users complying with the principles of harm reduction were included as well as individuals on opioid substitution therapy. Control group $(N=177)$ : patients without a history of IVDU, who were treated within the same time period.

The patients' data were extracted from the electronic patient database containing records of all scheduled, postponed and unscheduled patients' visits during the treatment and follow-up period. The recording of medical history at individual visits was based on a uniform template; all the patients were treated only by two physicians of the center (S. F. and J. S.); thus, all the analyzed data were mentioned in the medical records. Adherence to the medical appointments was assessed via the records in the hospital information system electronic diary. Drug accountability was checked at every visit of the center.

\section{Antiviral treatment choice}

All patients in both groups were treated with a combination of direct acting antivirals (DAA); a regimen containing interferon $\alpha$ was administered to none of the patients. All DAA combinations administered to the patients are listed in Table 1. The choice of the treatment regimen and its duration (8 or 12 weeks) was based on the following criteria: reimbursement by Czech Public Health Insurance at the time of treatment initiation, HCV genotype, HCV RNA baseline level, liver fibrosis stage (assessed by vibration controlled transient elastography, Fibroscan ${ }^{\circledR}$, Echosens, Paris, France) and potential drug-drug interactions with concomitant medication.

\section{Laboratory assessment}

$\mathrm{HCV}$ RNA was assessed by the Roche COBAS $^{\circledR}$ AmpliPrep/COBAS ${ }^{\circledR}$ TaqMan ${ }^{\circledR}$ HCV Quantitative Test v2.0 (Roche Molecular Systems Inc., Branchburg, NJ, USA) at baseline, at weeks 4,8 and 12 of therapy and 12 and 24 weeks after the end of therapy. HCV genotype was assessed before treatment initiation using the SIEMENS Versant ${ }^{\circledR}$ HCV Genotype 2.0 Assay (LiPA) (Siemens Healthcare Diagnostics Inc., Tarrytown, NY, USA).

\section{Compliance with ethical standards}

The study was approved by the Ethics Committee of Thomayer's Hospital and the Institute for Clinical and Experimental Medicine, Prague, Czech Republic, and was carried out in compliance with the Helsinki Declaration. The patients' informed consent was not required by local law because of the retrospective design of the study and the use of data from which the patients' identification information had been removed.

\section{Statistical analysis}

Treatment efficacy was assessed as intention-to-treat, and all patients were included in the statistical analysis in all timepoints. Continuous variables are presented as means and standard deviations, whereas categorical variables are expressed as frequencies (\%). Categorical data were analyzed using the Chi-square test. For continuous data, Student's $t$-test or the nonparametric Mann-Whitney test were used appropriately. Factors of treatment 
Table 1 Used antiviral treatment

\begin{tabular}{|c|c|c|c|}
\hline & PWID group $(N=101)$ & $\begin{array}{l}\text { Control group } \\
(N=177)\end{array}$ & $p$ \\
\hline Previous IFN-a treatment & $19(18.8 \%)$ & $69(39 \%)$ & 0.03 \\
\hline \multicolumn{4}{|l|}{ Direct-acting antivirals combination } \\
\hline $\begin{array}{l}\text { Paritaprevir/ritonavir + ombitasvir + dasabuvir } 8 \text { or } 12 \text { weeks }(75 / 50 / 12.5 / 250 \mathrm{mg} \text {, three pills in } \\
\text { the morning, one pill in the evening) }\end{array}$ & $41(40.6 \%)$ & $83(48.7 \%)$ & \multirow[t]{6}{*}{$<0.01$} \\
\hline Sofosbuvir + ledipasvir 8 or 12 weeks (400/90 mg, one pill once daily) & $18(17.8 \%)$ & $19(10.7 \%)$ & \\
\hline Grazoprevir + elbasvir 12 weeks (100/50 mg, one pill once daily) & $19(18.8 \%)$ & $57(32.2 \%)$ & \\
\hline Sofosbuvir + velpatasvir 12 weeks (400/100 mg, one pill once daily) & $18(17.8 \%)$ & $10(5.6 \%)$ & \\
\hline Sofosbuvir + velpatasvir + voxilaprevir 8 or 12 weeks (400/100/100 mg, one pill once daily) & $3(3.0 \%)$ & $4(1.4 \%)$ & \\
\hline Other & $2(2.0 \%)$ & $4(1.4 \%)$ & \\
\hline \multicolumn{4}{|l|}{ Treatment duration } \\
\hline 8 weeks & $27(26.7 \%)$ & $36(20.3 \%)$ & \multirow[t]{2}{*}{ N.S. } \\
\hline 12 weeks & $74(73.3 \%)$ & $141(79.7 \%)$ & \\
\hline Use of ribavirin (twice daily according to body weight, 800-1200 mg) & $19(18.8 \%)$ & $22(12.4 \%)$ & N.S. \\
\hline
\end{tabular}

$P$ value of $<0.05$ was considered statistically significant and the results are displayed in bold

$P W I D$ people who inject drugs group

adherence were examined using multivariate logistic regression analysis. All statistical analyses were twosided, and $p$ value of $<0.05$ was considered statistically significant throughout the study. Statistical analysis was performed using the GraphPad Prism version 8.2.1 for Mac, GraphPad Software, San Diego, California, USA, www.graphpad.com and $\mathrm{R}$ programming language version 3.2.0 (www.r-project.org).

\section{Methods to improve adherence to therapy}

PWID patients who were referred to therapy by harm reduction services were accompanied by employees of harm reduction centers or by peer workers, especially at the first visit. For all who started antiviral treatment, a 24-h helpline was available for support and consulting their medical condition. The appointments were planned taking into account patient's lifestyle and acceptability of job absenteeism. We minimized the number of appointments needed for treatment initiation: Blood sampling, transient elastography, ultrasound examination and the appointment with the physician took place within $1 \mathrm{~h}$. The blood draw was possible during the whole of the working day, when needed. Antiviral treatment was initiated immediately when HCV RNA and genotype results were available, ideally at the first visit, usually within 1 week.

All patients obtained advice on medication use with focus on regular drug intake, without skipping doses and the risks of premature termination and treatment interruption. All concomitant medications potentially influencing treatment efficacy were carefully reviewed. The patients were advised how to increase adherence to therapy: reminder alarms in the mobile phone, a link between medication and a regular daily activity (i.e., breakfast, arrival at work). If the patients missed their appointment, they were contacted by telephone or e-mail and the visit was rescheduled for the following day. All visits were planned 3 days before taking the last dose of dispensed medication.

\section{Results}

\section{Patients' demographic characteristics}

The demographic characteristics of both studied groups are summarized in Table 2. In the PWID group, there were significantly more males and the age of the patients was significantly lower in comparison with the control group. There were a comparable number of foreigners in both groups in whom Czech was not their native language. However, their level of Czech language was satisfactory, they all had a stable job and medical insurance. In the group of PWID, IVDU was taken as the most probable factor of $\mathrm{HCV}$ transmission; in the control group, $27.7 \%$ of patients were infected via blood transfusion before 1992, and nearly half of the patients in the control group did not report any potential risk factor for $\mathrm{HCV}$ infection.

More than one half of the patients in the PWID group (57.4\%) declared abstinence from illicit drug use of more than 5 years, and $18.8 \%$ of patients self-reported ongoing drug use. Two patients were included in the opioid substitution program with methadone. In the control group, a significantly higher number of patients had previously been unsuccessfully treated with an interferon $\alpha$-based regimen. 
Table 2 Demographic characteristics

\begin{tabular}{|c|c|c|c|}
\hline & PWID group $(N=101)$ & Control group $(N=177)$ & $p$ \\
\hline Male sex & $66(65.3 \%)$ & $91(51.4 \%)$ & 0.02 \\
\hline Age (years, median, range) & $40(22-68)$ & $59(22-87)$ & $<0.001$ \\
\hline Foreigners & $12(11.9 \%)$ & 37 (20.9\%) & N.S. \\
\hline \multicolumn{4}{|l|}{ Mode of transmission } \\
\hline Intravenous drug use & $101(100 \%)$ & & $<0.001$ \\
\hline Blood transfusion & & $49(27.7 \%)$ & \\
\hline Tattoo & & $11(62 \%)$ & \\
\hline Sexual transmission & & $2(1.1 \%)$ & \\
\hline Nosocomial acquisition & & $16(9.0 \%)$ & \\
\hline Professional exposure & & $13(7.4 \%)$ & \\
\hline Men having sex with men & & $4(2.3 \%)$ & \\
\hline Unknown & & $82(46.3 \%)$ & \\
\hline \multicolumn{4}{|l|}{ Abstinence } \\
\hline Recent or ongoing drug use & $19(18.8 \%)$ & N. A & \\
\hline$>1$ year & $24(23.8 \%)$ & & \\
\hline$>5$ years & $58(57.4 \%)$ & & \\
\hline \multicolumn{4}{|l|}{ Opioid substitution therapy } \\
\hline Methadone & $2(2 \%)$ & N. A & \\
\hline Buprenorphine & $0(0 \%)$ & & \\
\hline \multicolumn{4}{|l|}{ HCV genotype } \\
\hline $1 a$ & $34(33.7 \%)$ & $13(7.3 \%)$ & $<0.001$ \\
\hline $1 b$ & 45 (44.5\%) & $148(83.7 \%)$ & \\
\hline 3 & $19(18.8 \%)$ & $13(7.3 \%)$ & \\
\hline Other & $3(3 \%)$ & $3(1.7 \%)$ & \\
\hline Baseline HCV RNA (IU/mL, median, range) & $763,000(35-13,500,000)$ & $1,340,000(912-24,900,000)$ & 0.04 \\
\hline \multicolumn{4}{|l|}{ Fibrosis stage (Metavir score) } \\
\hline F0-F1 & $41(40.6 \%)$ & $72(40.7 \%)$ & \\
\hline $\mathrm{F} 2$ & $27(26.7 \%)$ & $29(16.4 \%)$ & 0.02 \\
\hline F3 & $13(12.9 \%)$ & $14(7.9 \%)$ & \\
\hline F4 & $20(19.8 \%)$ & $62(35.0 \%)$ & \\
\hline
\end{tabular}

$P$ value of $<0.05$ was considered statistically significant and the results are displayed in bold

$P W I D$ people who inject drugs group

$\mathrm{HCV}$ genotype $1 \mathrm{~b}$ was the most prevalent in both groups, but the genotype distribution differed significantly between groups (a higher frequency of genotypes $1 \mathrm{a}$ and 3 in the PWID group). PWID presented with a less advanced liver disease and had lower baseline $\mathrm{HCV}$ viral load in comparison with the control group.

\section{Patients' social characteristics}

The data are summarized in Table 3. In the PWID group, a significant number of patients reported imprisonment and more often reported an amateur tattoo. In the PWID group, a significantly higher rate of patients smoked and reported harmful alcohol drinking (a daily dose of more than $20 \mathrm{~g}$ and $30 \mathrm{~g}$ of alcohol in women and men, respectively) [18], and $6.9 \%$ of patients in the PWID group had a history of alcohol addiction therapy. The patients with a dual diagnosis represented $28.7 \%$ of the PWID group.

There were 22 PWID patients self-referred to HCV therapy based on information obtained from media or successfully treated friends. The PWID were more often unemployed and had a significantly lower education in comparison with the control group. They more often reported unstable housing, but none of them was homeless.

\section{Antiviral treatment efficacy}

SVR 12 weeks after the end of therapy (SVR 12) which is considered as cure of HCV infection [2] was achieved by $98 \%$ of patients in the PWID group. Two non-SVR patients were lost to follow-up. In the control group, the SVR rate was identically $98 \%$, four patients experienced 
Table 3 Social characteristics

\begin{tabular}{|c|c|c|c|}
\hline & PWID group $(N=101)$ & Control group $(N=177)$ & $p$ \\
\hline Imprisonment & $7(6.9 \%)$ & $1(0.6 \%)$ & 0.004 \\
\hline Tattoo & $50(49.5 \%)$ & $12(6.8 \%)$ & $<0.001$ \\
\hline Smoking & $69(68.3 \%)$ & $37(20.9 \%)$ & $<0.001$ \\
\hline Harmful drinking history & $13(12.9 \%)$ & $7(4.0 \%)$ & 0.008 \\
\hline Alcohol addiction treatment history & $7(6.9 \%)$ & $2(1.1 \%)$ & \\
\hline Dual diagnosis & $29(28.7 \%)$ & $9(5.1 \%)$ & $<0.001$ \\
\hline \multicolumn{4}{|l|}{ Reference to treatment } \\
\hline Infectious diseases specialist & $34(33.7 \%)$ & $68(38.4 \%)$ & $<0.001$ \\
\hline Gastroenterologist & $25(24.8 \%)$ & $67(37.8 \%)$ & \\
\hline General practitioner/other specialist & $11(10.9 \%)$ & $30(17 \%)$ & \\
\hline Addiction specialist, psychiatrist & $9(8.9 \%)$ & $0(0 \%)$ & \\
\hline Self-reference & $22(21.8 \%)$ & $12(6.8 \%)$ & \\
\hline \multicolumn{4}{|l|}{ Job } \\
\hline Stable & $56(56.3 \%)$ & $90(50.8 \%)$ & $<0.001$ \\
\hline Unstable & $5(5.0 \%)$ & $0(0 \%)$ & \\
\hline Unemployed & $13(12.9 \%)$ & $4(1.4 \%)$ & \\
\hline Retired & $1(1 \%)$ & $75(43.2 \%)$ & \\
\hline Disability leave & $15(14.9 \%)$ & $7(4.0 \%)$ & \\
\hline Maternity leave & $11(9.9 \%)$ & $1(0.6 \%)$ & \\
\hline \multicolumn{4}{|l|}{ Education } \\
\hline Primary & $20(19.8 \%)$ & $4(1.4 \%)$ & $<0.001$ \\
\hline Secondary, qualified worker & $57(56.4 \%)$ & $92(52.0 \%)$ & \\
\hline Secondary, leaving examination & $19(18.8 \%)$ & $64(38.0 \%)$ & \\
\hline University & $0(0 \%)$ & $15(8.5 \%)$ & \\
\hline Unknown & $5(5.0 \%)$ & $2(1.1 \%)$ & \\
\hline \multicolumn{4}{|l|}{ Housing } \\
\hline Stable & $86(85.1 \%)$ & $176(99.4 \%)$ & $<0.001$ \\
\hline Unstable & $15(14.9 \%)$ & $0(0 \%)$ & \\
\hline Homeless & $0(0 \%)$ & $1(0.6 \%)$ & \\
\hline
\end{tabular}

$P$ value of $<0.05$ was considered statistically significant and the results are displayed in bold

$P W I D$ people who inject drugs group

relapse of $\mathrm{HCV}$ infection and one patient was lost to follow-up. The SVR 12 rate did not differ significantly between groups (Table 4).

SVR 24 was achieved by $88.1 \%$ of patients in the PWID group, one patient relapsed, one patient got re-infected, and ten patients were lost to follow-up at 24 weeks posttreatment. In the control group, SVR 24 rate was $92.1 \%$, altogether, nine patients relapsed and five were lost to follow-up. The SVR 24 rate did not differ significantly between groups despite the higher number of lost to follow-up patients.

\section{Adherence to therapy}

The data are summarized in Table 4. All but one patient terminated the whole course of 8- or 12-week therapy on time or a few days later. Two and four percent of patients terminated late in the PWID and control group, respectively. In the PWID group, the maximal delay was 3 days and a 7-day delay was reported in one patient in the control group, who interrupted therapy due to diarrhea in ulcerative colitis. Both patients in the PWID group missed three doses of antiviral medication.

PWID patients had a significantly higher number of postponed medical appointments (28.7\% patients vs. $4 \%$ in the control group, $p=0.001$ ); however, postponing visits led in only one PWID patient to a lack of medication and skipped dosing. In the control group, two patients postponed their appointments and ran out of medication. The difference in missed visits in the follow-up period was not statistically significant between groups at week 12 after the end of therapy, whereas PWID patients missed the SVR 24 visit statistically more often $(10.9 \%$ vs. $1.1 \%, p=0.004)$. The achieved SVR 12 according to 
Table 4 Treatment efficacy and adherence to therapy

\begin{tabular}{|c|c|c|c|}
\hline & PWID group & Control group & $p$ \\
\hline SVR 12 & 99 (98\%) & $172(98 \%)$ & N.S. \\
\hline Lost to follow-up & $2(2.0 \%)$ & $1(0.6 \%)$ & \\
\hline Relapse & $0(0 \%)$ & $4(1.4 \%)$ & \\
\hline SVR 24 & $89(88.1 \%)$ & $163(92.1 \%)$ & N.S. \\
\hline Lost to follow-up & $10(9.9 \%)$ & $5(2.8 \%)$ & \\
\hline Relapse & $1(1 \%)$ & $9(5.1 \%)$ & \\
\hline Reinfection & $1(1 \%)$ & $0(0 \%)$ & \\
\hline SVR 12 according to adherence & & & N.S. \\
\hline $100 \%$ adherent & $69(100 \%)$ & $153(95.6 \%)$ & \\
\hline Non-100\% adherent & $30(93.8 \%)$ & $15(88.2 \%)$ & \\
\hline Treatment termination on time & $99(98 \%)$ & $169(95.5 \%)$ & N.S. \\
\hline Premature treatment termination & $0(0 \%)$ & $1(0.6 \%)$ & N.S. \\
\hline Postponed treatment termination & $2(2.0 \%)$ & $7(4.0 \%)$ & N.S. \\
\hline \multicolumn{4}{|l|}{ Delay (days) } \\
\hline Patient 1 & 3 & & \\
\hline Patient 2 & 3 & & \\
\hline Patient 3 & & 2 & \\
\hline Patient 4 & & 1 & \\
\hline Patient 5 & & 1 & \\
\hline Patient 6 & & 1 & \\
\hline Patient 7 & & 7 & \\
\hline Patient 8 & & 2 & \\
\hline Patient 9 & & 2 & \\
\hline \multicolumn{4}{|l|}{ Missed doses (no. of patients) } \\
\hline 1 dose & 0 & 3 & N.S. \\
\hline 2 doses & 0 & 3 & \\
\hline 3 doses & 2 & 0 & \\
\hline 7 doses & 0 & 1 & \\
\hline Postponed visits (no. of patients) & $29(28.7 \%)$ & $7(4.0 \%)$ & $<0.001$ \\
\hline 1 visit & 17 & 7 & \\
\hline 2 visits & 8 & 0 & \\
\hline 3 visits & 4 & 0 & \\
\hline Missed visits (no. of patients) & $13(12.9 \%)$ & $6(3.4 \%)$ & 0.006 \\
\hline 1 visit & 11 & 6 & \\
\hline 2 visits & 2 & 0 & \\
\hline Lack of medication (no. of patients) & $1(1 \%)$ & $2(1.1 \%)$ & N.S. \\
\hline Patient 1 (missed doses) & 3 & & \\
\hline Patient 2 (missed doses) & & 2 & \\
\hline Patient 3 (missed doses) & & 2 & \\
\hline Missed visit 12 weeks post-treatment (SVR 12) & $2(2 \%)$ & $1(0.6 \%)$ & N.S. \\
\hline Missed visit 24 weeks post-treatment (SVR 24) & $11(10.9 \%)$ & $2(1.1 \%)$ & 0.004 \\
\hline
\end{tabular}

$P$ value of $<0.05$ was considered statistically significant and the results are displayed in bold $P W I D$ people who inject drugs group, SVR sustained virological response

achieved adherence to therapy differed neither in the PWID nor in the control group.

Analysis of factors contributing to an absolute adherence to therapy was performed for all patients and for each group separately. In multivariate analysis of the whole cohort of treated patients, IVDU was not a factor contributing to a worse adherence to treatment. Stable housing was a significant predictor of excellent adherence $(p<0.05$; odds ratio (OR) 5.00, 95\% confidence interval (CI) 1.40-19.80), whereas being a foreigner 


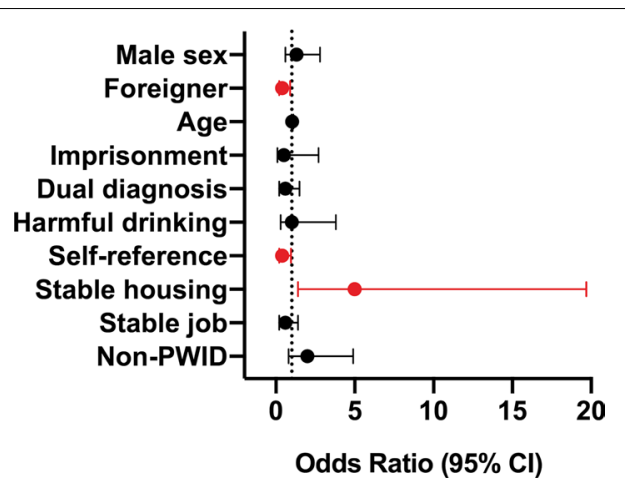

Fig. 1 Factors determining adherence to therapy (the whole cohort of patients). Cl confidence interval, PWID people who inject drugs group

$(p<0.05$; OR $0.39,95 \%$ CI $0.17-0.94)$ and self-referred to therapy $(p<0.05$; OR $0.40,95 \%$ CI $0.17-0.99)$ negatively influenced adherence to treatment (Fig. 1). In the PWID group, older age $(p<0.05$; OR $1.07,95 \%$ CI $1.00-1.20)$ and stable housing ( $p<0.01$; OR 9.70, 95\% CI 2.10-56.20) were factors positively contributing to adherence. On the other hand, a stable job was a factor negatively influencing adherence $(p<0.05$; OR $0.24,95 \%$ CI $0.06-0.81)$ (Fig. 2A). In the control group, none of the analyzed demographic and social factors had a significant impact on adherence to therapy (Fig. 2B).

\section{Discussion}

In the interferon era, PWID used to be regarded as a special population, difficult to treat, with presumed lower adherence to therapy and lower treatment efficacy [10]. Even though aware of their infection, they were not referred to therapy for different reasons: low treatment adherence, a high risk of treatment-associated adverse events, worse treatment tolerability or a medical contraindication to therapy, i.e., dual diagnosis. These individuals now come to get DAA therapy, but the treatment uptake remains low and treatment accessibility is limited because of many barriers to $\mathrm{HCV}$ care in this vulnerable group of patients from the side of physicians, health-care payers and the negative opinion on the reimbursement of therapy by non-professional community $[11,14,19]$. The aim of our study was to support the evidence that the efficacy of therapy in PWID is high and that the financial resources are invested effectively. Achieving cure of people in the epidemiologically highrisk group, we decrease the risk of disease transmission $[4,20,21]$.

The above-described group represents a pilot cohort of PWID treated with DAA. Most of the patients reported a long period of abstinence, only a minority of them reported ongoing illicit drug use, and therefore, we assumed a superior adherence to therapy within this subgroup of difficult-to-treat patients to whom antiviral therapy had been denied so far. The aim of this pilot study was to break the myth of PWID non-adherence leading to inferior efficacy of therapy. Our data suggest that treatment is feasible when appropriate methods improving adherence to therapy and motivation are applied, especially in patients with ongoing drug use, and may encourage further centers in successful treatment of PWID and support the willingness to pay for DAA regimens by health insurance companies.

The efficacy of therapy (SVR 12) in the PWID group was $98 \%$, comparable with the control group and with the results of registration trials and real-world studies [22-28]. The results unequivocally justify treatment of PWID. The PWID group patients in our cohort were significantly younger, with a less advanced liver disease. Achieving cure of $\mathrm{HCV}$ infection, we can prevent
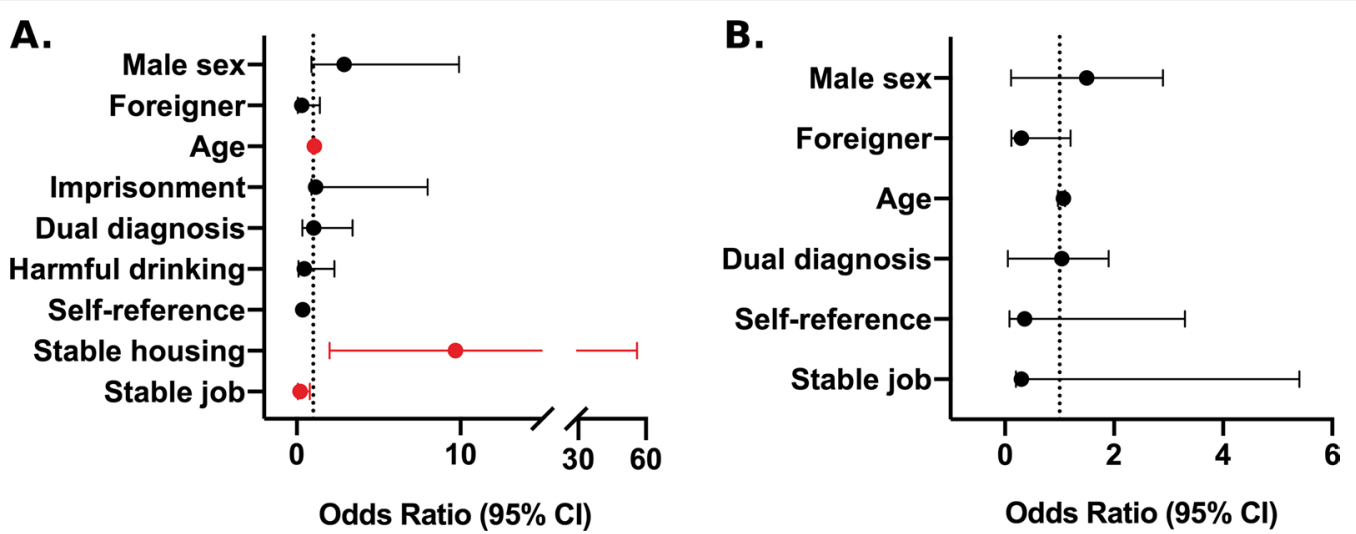

Fig. 2 Factors determining adherence to therapy (A people who inject drugs group, B control group). Cl confidence interval 
progression of liver disease with future decrease of liverrelated morbidity and mortality $[4,29]$.

Early after the introduction of DAA into routine clinical practice in the Czech Republic, in 2015 and 2016, the rate of patients entering DAA therapy was lower in comparison with recent data. Patients with advanced liver disease, most of them with cirrhosis, organ transplant recipients and patients on maintenance hemodialysis had been prioritized [30, 31]. PWID had still been treated with peginterferon- $\alpha$ or had not been treated owing to medical contraindications, such as dual diagnosis. Over a period of 4 years, the percentage of treatment uptake of PWID has increased and represents nowadays more than $75 \%$ of treated patients. There are no more treatment restrictions concerning severity of liver disease, but the only criteria are motivation of the patient and adherence to therapy [32].

We consider the adherence to therapy of our patients to be very good. The adherence to therapy in the PWID group was worse only in the number of missed appointments, not in the use of medication. The patients were aware of the necessity of regular use of medication and came accurately to the appointments when new medication was dispensed. On the other hand, their adherence decreased after SVR 12 visit, after being cured. We attribute this fact to the younger age of PWID patients and the sensation of good health. In the control group, patients were older, more often with cirrhosis, undergoing surveillance of hepatocellular carcinoma; consequently, their motivation in the regular follow-up was higher and medically understandable.

In the PWID, the factors positively influencing adherence were older age and, above all, stable housing. It is in accordance with the fact that "housing first" approach represents one of the most important strategies of social integration of PWID. On the other hand, a stable job was a factor predicting worse adherence, leading to a higher number of postponed and missed visits. In the Czech Republic, HCV infection is still perceived as a highly stigmatizing disease. Most $\mathrm{HCV}$-infected patients are reluctant to confess their diagnosis, being afraid if losing their job. Therefore, this fact is an important obstacle to scheduling and adherence to treatment visits.

Our results, SVR 12 and adherence, are better than in the above-cited studies [15-17]. This fact can be attributed not only to the patients' motivation but also to the support of physicians and nurses. We have had a longterm experience with HCV therapy including PWID group, and we have had a long-term collaboration with low-threshold drug addiction centers, rehabilitation centers and therapeutic communities. Thanks to this collaboration, we pointed out the factors contributing to a better adherence to therapy and every patient had a tailored approach.

In the PWID group, IVDU was presumed to be the most important route of $\mathrm{HCV}$ transmission. However, most PWID had been exposed to more than one risk factors for $\mathrm{HCV}$ transmission, as amateur tattoo, sexual transmission or imprisonment. They should be aware of other risk factors for $\mathrm{HCV}$ transmission which may represent a potential source of reinfection after successful course of therapy. In close collaboration with harm reduction services centers and their employees, in our group of treated patients, the implemented harm reduction strategies included not only providing sterile needles, syringes and other injection equipment, but also education about overdose prevention, safer injection practices, basic health services (including vaccination), referrals for substance use disorder treatment and job and housing counseling services.

\section{Conclusions}

In PWID, treatment efficacy was excellent and was comparable with SVR of the control group. Stable housing and older age were the major factors contributing to a better adherence to therapy.

\section{Abbreviations}

Cl: Confidence interval; DAA: Direct-acting antivirals; HCV: Hepatitis C virus infection; IVDU: Intravenous drug use; OR: Odds ratio; PWID: People who inject drugs; SVR: Sustained virological response.

\section{Acknowledgements}

The authors thank referring physicians and social workers for their support.

\section{Authors' contributions}

JS provided clinical and laboratory data and wrote and revised the manuscript; SF provided clinical and laboratory data, performed statistical analysis and wrote and revised the manuscript; ZJ provided clinical data and wrote the manuscript; GJ provided clinical data and revised the manuscript; MK performed HCV RNA analysis and genotyping; and DM performed statistical analysis and drew the figures. All authors read and approved the final manuscript.

\section{Funding}

The study was supported by the project (Ministry of Health, Czech Republic) for development of research organization 00023001 (Institute for Clinical and Experimental Medicine, Prague, Czech Republic)_institutional support.

\section{Availability of data and materials}

The datasets used and analyzed in study are available from the corresponding author by request.

\section{Declarations}

Ethics approval and consent to participate

The study was approved by the Ethics Committee of Thomayer's Hospital and the Institute for Clinical and Experimental Medicine, Prague, Czech Republic.

Consent for publication

Not applicable. 


\section{Competing interests}

The authors declare that they have no competing interests.

\section{Author details}

${ }^{1}$ Department of Hepatogastroenterology, Institute for Clinical and Experimental Medicine, Videnska 1958/9, 14021 Prague, Czech Republic. ${ }^{2}$ Psychiatric Hospital Havlickuv Brod, Havlickuv Brod, Czech Republic. ${ }^{3}$ Addiction Centre Prague, Prague, Czech Republic. ${ }^{4}$ Institute of Medical Biochemistry and Laboratory Diagnostics, First Faculty of Medicine Charles University and General University Hospital in Prague, Prague, Czech Republic. ${ }^{5}$ Cardiothoracic Anaesthesiology and Intensive Care, Department of Anaesthesiology and Intensive Care Medicine, Institute for Clinical and Experimental Medicine, Prague, Czech Republic. ${ }^{6}$ First Faculty of Medicine, Charles University, Prague, Czech Republic.

Received: 31 May 2020 Accepted: 22 June 2021

Published online: 30 June 2021

\section{References}

1. Degenhardt L, Peacock A, Colledge S, Leung J, Grebely J, Vickerman P, Stone J, Cunningham EB, Trickey A, Dumchev K, et al. Global prevalence of injecting drug use and sociodemographic characteristics and prevalence of HIV, HBV, and HCV in people who inject drugs: a multistage systematic review. Lancet Glob Health. 2017;5(12):e1192-207.

2. EASL. EASL recommendations on treatment of hepatitis C 2018. J Hepatol. 2018;69:461-511.

3. Grebely J, Robaeys G, Bruggmann P, Aghemo A, Backmund M, Bruneau J, Byrne J, Dalgard O, Feld JJ, Hellard M, et al. Recommendations for the management of hepatitis $C$ virus infection among people who inject drugs. Int J Drug Policy. 2015;26(10):1028-38.

4. Frankova S, Urbanek P, Husa P, Nemecek V, Razavi H, Razavi-Shearer D, Chlibek R, Sperl J. Chronic hepatitis C in the Czech Republic: forecasting the disease burden. Cent Eur J Public Health. 2019;27(2):93-8.

5. Edlin BR. Perspective: test and treat this silent killer. Nature. 2011;474(7350):S18-19.

6. Nelson PK, Mathers BM, Cowie B, Hagan H, Des Jarlais D, Horyniak D, Degenhardt L. Global epidemiology of hepatitis B and hepatitis C in people who inject drugs: results of systematic reviews. Lancet. 2011;378(9791):571-83.

7. Chlibek R, Smetana J, Sosovickova R, Gal P, Dite P, Stepanova V, Pliskova L, Plisek S. Prevalence of hepatitis C virus in adult population in the Czech Republic — time for birth cohort screening. PLoS ONE. 2017;12(4):e0175525.

8. https://www.drogy-info.cz/data/obj_files/32962/837/NZdrogy2017_web18 1207.pdf.

9. Powell DW, Abramson BZ, Balint JA, Belle S, Bloomer JR, Diehl AK, Frakes JT, Garcia-Tsao G, Hook EW, Lusher JM, Popovsky MA. National Institutes of Health Consensus Development Conference Panel statement: management of hepatitis C. Hepatology. 1997;26(3 Suppl 1):2S-10S.

10. Mehta SH, Genberg BL, Astemborski J, Kavasery R, Kirk GD, Vlahov D, Strathdee SA, Thomas DL. Limited uptake of hepatitis $C$ treatment among injection drug users. J Community Health. 2008;33(3):126-33.

11. Iversen J, Grebely J, Catlett B, Cunningham P, Dore GJ, Maher L. Estimating the cascade of hepatitis $C$ testing, care and treatment among people who inject drugs in Australia. Int J Drug Policy. 2017;47:77-85.

12. Socias ME, Ti L, Wood E, Nosova E, Hull M, Hayashi K, Debeck K, Milloy MJ. Disparities in uptake of direct-acting antiviral therapy for hepatitis $C$ among people who inject drugs in a Canadian setting. Liver Int. 2019;39(8):1400-7.

13. Tsui Jl, Miller CM, Scott JD, Corcorran MA, Dombrowski JC, Glick SN. Hepatitis $C$ continuum of care and utilization of healthcare and harm reduction services among persons who inject drugs in Seattle. Drug Alcohol Depend. 2019;195:114-20.

14. Bruggmann $\mathrm{P}$, Litwin $\mathrm{AH}$. Models of care for the management of hepatitis $\mathrm{C}$ virus among people who inject drugs: one size does not fit all. Clin Infect Dis. 2013;57(Suppl 2):S56-61.

15. Dore GJ, Altice F, Litwin AH, Dalgard O, Gane EJ, Shibolet O, Luetkemeyer A, Nahass R, Peng CY, Conway B, et al. Elbasvir-Grazoprevir to treat hepatitis C virus infection in persons receiving opioid agonist therapy: a randomized trial. Ann Intern Med. 2016;165(9):625-34.

16. Grebely J, Dalgard O, Conway B, Cunningham EB, Bruggmann P, Hajarizadeh B, Amin J, Bruneau J, Hellard M, Litwin AH, et al. Sofosbuvir and velpatasvir for hepatitis $C$ virus infection in people with recent injection drug use
(SIMPLIFY): an open-label, single-arm, phase 4, multicentre trial. Lancet Gastroenterol Hepatol. 2018;3(3):153-61.

17. Kattakuzhy S, Mathur P, Gross C, Silk R, Hil K, Nussdorf L, Chaudhury CS, Sternberg D, Masur H, Kottilil S, et al. High SVR in PWID with HCV despite imperfect medication adherence: data from the anchor study. Hepatology. 2018;68(S1):1-183.

18. EASL. EASL clinical practice guidelines: management of alcohol-related liver disease. J Hepatol. 2018;69:154-81.

19. Falade-Nwulia O, Irvin R, Merkow A, Sulkowski M, Niculescu A, Olsen Y, Stoller K, Thomas DL, Latkin C, Mehta SH. Barriers and facilitators of hepatitis C treatment uptake among people who inject drugs enrolled in opioid treatment programs in Baltimore. J Subst Abuse Treat. 2019;100:45-51.

20. Phillips C, Schulkind J, O'Sullivan M, Edelman N, Smith HE, Verma S, Jones CJ. Improving access to care for people who inject drugs: qualitative evaluation of project ITTREAT—an integrated community hepatitis C service. J Viral Hepat. 2019;27:176-87.

21. Olafsson S, Tyrfingsson T, Runarsdottir $V$, Bergmann OM, Hansdottir I, Bjornsson ES, Johannsson B, Sigurdardottir B, Fridriksdottir RH, Love A, et al. Treatment as Prevention for Hepatitis C (TraP Hep C) - a nationwide elimination programme in Iceland using direct-acting antiviral agents. J Intern Med. 2018;283(5):500-7.

22. Feld JJ, Jacobson IM, Hezode C, Asselah T, Ruane PJ, Gruener N, Abergel A, Mangia A, Lai CL, Chan HL, et al. Sofosbuvir and velpatasvir for HCV genotype 1, 2, 4, 5, and 6 infection. N Engl J Med. 2015:373(27):2599-607.

23. Forns $X$, Lee SS, Valdes J, Lens S, Ghalib R, Aguilar H, Felizarta F, Hassanein T, Hinrichsen H, Rincon D, et al. Glecaprevir plus pibrentasvir for chronic hepatitis C virus genotype 1,2,4,5, or 6 infection in adults with compensated cirrhosis (EXPEDITION-1): a single-arm, open-label, multicentre phase 3 trial. Lancet Infect Dis. 2017;17:1062-8.

24. Foster GR, Afdhal N, Roberts SK, Brau N, Gane EJ, Pianko S, Lawitz E, Thompson A, Shiffman ML, Cooper C, et al. Sofosbuvir and velpatasvir for HCV genotype 2 and 3 infection. N Engl J Med. 2015;373(27):2608-17.

25. Kowdley KV, Gordon SC, Reddy KR, Rossaro L, Bernstein DE, Lawitz E, Shiffman ML, Schiff E, Ghalib R, Ryan M, et al. Ledipasvir and sofosbuvir for 8 or 12 weeks for chronic HCV without cirrhosis. N Engl J Med. 2014;370(20):1879-88.

26. Kwo PY, Poordad F, Asatryan A, Wang S, Wyles DL, Hassanein T, Felizarta F, Sulkowski MS, Gane E, Maliakkal B, et al. Glecaprevir and pibrentasvir yield high response rates in patients with HCV genotype 1-6 without cirrhosis. J Hepatol. 2017;67(2):263-71.

27. D'Ambrosio R, Pasulo L, Puoti M, Vinci M, Schiavini M, Lazzaroni S, Soria A, Gatti F, Menzaghi B, Aghemo A, et al. Real-world effectiveness and safety of glecaprevir/pibrentasvir in 723 patients with chronic hepatitis C. J Hepatol. 2019;70(3):379-87.

28. Berg T, Naumann U, Stoehr A, Sick C, John C, Teuber G, SchiffelholzW, Mauss S, Lohmann K, Konig B, et al. Real-world effectiveness and safety of glecaprevir/pibrentasvir for the treatment of chronic hepatitis $C$ infection: data from the German Hepatitis C-Registry. Aliment Pharmacol Ther. 2019;49(8):1052-9.

29. Skoupá J, Urbánek P. A comparison of cost-effectiveness analysis of two strategies - immediate and delayed initiation of treatment of hepatitis C in the Czech Republic. Gastroenterol Hepatol. 2018;72(1):58-65.

30. Sperl J, Frankova S, Kreidlova M, Merta D, Tothova M, Spicak J. Combination of sofosbuvir and daclatasvir in the treatment of genotype 3 chronic hepatitis $C$ virus infection in patients on maintenance hemodialysis. Ther Clin Risk Manag. 2017;13:733-8.

31. Sperl J, Kreidlova M, Merta D, Chmelova K, Senkerikova R, Frankova S. Paritaprevir/ritonavir/ombitasvir plus dasabuvir regimen in the treatment of genotype 1 chronic hepatitis $C$ infection in patients with severe renal impairment and end-stage renal disease: a real-life cohort. Kidney Blood Press Res. 2018;43(2):594-605

32. Urbanek P, Frankova S, Husa P, Sperl J, Plisek S, Roznovsky L, Kumpel P. Standard diagnostic and therapeutic approach to chronic hepatitis C virus (HCV) infection—guidelines. Gastroenterol Hepatol. 2019;73(2):101-25.

\section{Publisher's Note}

Springer Nature remains neutral with regard to jurisdictional claims in published maps and institutional affiliations. 